\title{
Effects of colorectal endoscopic submucosal dissection on treatment for $\mathrm{T}$ is carcinoma
}

\author{
Yuichi Tomiki*, Kumpei Honjo, Kazumasa Kure, Kosuke Mizukoshi, Masaya Kawai, Shun Ishiyama, Kiichi Sugimoto, Masanobu Tanaka, and \\ Kazuhiro Sakamoto \\ Department of Coloproctological Surgery, Juntendo University, Faculty of Medicine, Japan
}

\begin{abstract}
Objective: From the viewpoint of surgery, this study examined the effects of colorectal endoscopic submucosal dissection (ESD) on treatment for Tis carcinoma over the past 10 years since the technique was adopted.

Materials and methods: Among the 3,826 colorectal cancer patients treated at Juntendo University within the 20-year period between 1996 and 2015 . The total number of colorectal ESD performed within the 10-year period after its adoption in 2006 was 734 . Within the 20 -year period, the 495 diagnosed with Tis carcinoma were classified into 2 groups: 216 and 279 treated before and after adoption of colorectal ESD in 2006, respectively. The effects of colorectal ESD on treatment for Tis carcinoma after adoption were examined by clinically comparing such carcinoma patients and methods to treat them.

Results: The percentage of surgical procedures for Tis carcinoma decreased from 5.5 to $0.4 \%(p<0.01)$ after the adoption of colorectal ESD 10 years previously, while that of endoscopic procedures increased to $97.1 \%$. The most frequent method to treat Tis carcinoma before adoption was snare polypectomy with endoscopic mucosal resection (EMR), at 141 (65.3\%), followed by laparotomy, at 54 (25.0\%), laparoscopic surgery, at 18 (8.3\%), and transanal surgery, at 3 (1.4\%). Among the latter, colorectal ESD was the most frequent method, at 154 (55.2\%), while the number of polypectomy with EMR decreased to $117(41.9 \%)$. The number of surgical procedures was $8(2.9 \%)$.

Conclusion: From the surgical viewpoint, the merit of colorectal ESD may be further reducing the invasiveness of treatment for Tis carcinoma by reducing the use of surgical procedures.
\end{abstract}

\section{Introduction}

In Japan, early-stage colorectal cancers are classified into intramucosal (Tis) and submucosal (T1) carcinomas [1]. While T1 colorectal carcinoma has been reported to involve lymph node metastasis in approximately $10 \%$ [2-4], Tis colorectal carcinoma is not associated with a risk of lymph node or distant metastasis, in general, excluding special cases [5]. Therefore, it is desirable to treat Tis carcinoma endoscopically, rather than surgically. However, the incidence of local recurrence after endoscopic piecemeal resection for lesions which endoscopic en-bloc resection is difficult is high, at approximately 20\% [6-8]. Furthermore, some of such lesions are overtreated with surgical procedures even when they are identified as Tis carcinomas for various reasons, such as "a large tumor diameter" and "difficulty in snaring". These problems may be resolved by colorectal endoscopic submucosal dissection (ESD), which is a useful treatment method allowing en-bloc resection even for lesions that cannot be removed by conventional colonoscopic snare polypectomy, and has been used as an insurance-covered procedure since 2012 in Japan [9]. With the generalization of colorectal ESD, an increasing number of lesions are cured by endoscopic resection, consequently increasing demands for minimally invasive procedures to treat colorectal tumors $[10,11]$.

In our department, colorectal ESD was initiated in 2006, and we have the impression that the number of Tis carcinomas surgically treated for various reasons, such as difficulty in performing endoscopic resection, has decreased since that time. From the surgical viewpoint, this study examined the effects of colorectal ESD on treatment for Tis carcinoma over the past 10 years since the technique was adopted.

\section{Materials and methods}

Among the 3,826 colorectal cancer patients treated at the Department of Coloproctological Surgery, Juntendo University (Tokyo, Japan) within the 20-year period between 1996 and 2015. Written informed consent was obtained from the all patients.

From 2006 to 2015, we performed colorectal ESD in 734 patients within the 10-year period. Regarding the indications of colorectal ESD, those specified by the Colorectal ESD Standardization Implementation Working Group and Colorectal ESD/EMR Guidelines established by the Japan Gastroenterological Endoscopy Society were followed: 20 $\mathrm{mm}$ or larger tumors requiring endoscopic en-bloc resection [10]. Colorectal ESD was also applied to tumors smaller than $20 \mathrm{~mm}$ for which en-bloc resection using a normal snare was difficult to apply. The patients were 424 males and 310 females, with a mean age of $67.5 \pm$

Correspondence to: Yuichi Tomiki, Department of Coloproctological Surgery, Juntendo University, Faculty of Medicine, Tokyo, Japan, Tel: +81-38133111; Fax: +81-38130731; E-mail: tomiki@juntendo.ac.jp

Key words: colorectal neoplasms, endoscopic procedure, endoscopic submucosal dissection, surgical procedure

Received: April 02, 2016; Accepted: April 20, 2016; Published: April 23, 2016 
11.0 years (range, 29-94 years). Of the 734 tumors, 577 were located in the colon and 157 were in the rectum. The average tumor size was $30.7 \pm 15.4 \mathrm{~mm}$ (range, $4-130 \mathrm{~mm}$ ), and the average operation time was $81.8 \pm 88.9 \mathrm{~min}$ (range, 5-1440 $\mathrm{min}$ ). The rate of en-bloc resection was $91.6 \%$. The pathological diagnosis was as follows: 468 tumors were adenoma, 154 tumors were intramucosal carcinoma, and 93 tumors were carcinoma with submucosal invasion. Colorectal ESD was performed in 16 cases of rectal neuroendocrine tumor (carcinoid) and 3 cases of lipoma.

Regarding procedural accidents due to ESD in the 734 patients, intraoperative perforation occurred in 21 (2.9\%). Micro-perforation was closed by endoscopic clipping and manifested no symptoms in some patients. Free air was suspected on postoperative imaging in 6 patients $(0.8 \%)$.

Post-ESD bleeding occurred in 14 patients (1.9\%). All perforation and bleeding cases were conservatively remitted and no patient required emergent surgery (Table 1).

Within the 20-year period, the 495 tumors diagnosed with Tis carcinoma (intramucosal adenocarcinoma, as defined in Japanese guidelines [11]), were studied. The 495 Tis carcinoma patients were classified into 2 groups: 216 and 279 treated before and after adoption, respectively.

The effects of colorectal ESD on treatment for Tis carcinoma after adoption were examined by clinically comparing such carcinoma patients and methods to treat them. All values are shown as the mean $\pm \mathrm{SD}$ (range). Statistical analysis was performed using chi-square test, and t-test, in addition to JMP 9.0 (SAS Institute Inc., Cary, NC, USA). The significance level was set at $\mathrm{p}<0.05$ in all settings.

\section{Results}

\section{Background of Tis carcinomas}

Before the adoption of colorectal ESD, 216 (14.1\%) out of the 1,537 patients had been diagnosed with Tis carcinoma. After adoption, such a diagnosis was provided for 279 (12.2\%) out of the 2,289 patients. Although the number of Tis carcinomas was higher after adoption of colorectal ESD, reflecting an increase in the incidence of colorectal cancer, there were no differences in their numbers as a percentage of all colorectal cancers. While differences were not observed in patients'

Table 1: Clinicopathological factors of 734 colorectal ESDs in our institution.

\begin{tabular}{|c|c|c|}
\hline Clinicopathological factors & $\mathbf{n = 7 3 4}$ & \\
\hline Age, median (range), years & $67.5 \pm 11.0$ & $(29-94)$ \\
\hline Sex (M:F ratio) & 424 & $: 310$ \\
\hline Tumor location, $\mathrm{n}(\%)$ & & $(77.0 \%)$ \\
\hline Colon & 565 & $(23.0 \%)$ \\
\hline Rectum & 169 & $(4-130)$ \\
\hline Tumor size (range), mm & $30.7 \pm 15.4$ & $(5-1440)$ \\
\hline Procedure time (range), min & $81.8 \pm 88.9$ & $(91.6 \%)$ \\
\hline En block resection, $n(\%)$ & 672 & $(63.7 \%)$ \\
\hline Pathological diagnosis, $\mathrm{n}(\%)$ & & $(21.0 \%)$ \\
\hline Adenoma & 468 & $(12.7 \%)$ \\
\hline Intramucosal carcinoma & 154 & $(2.2 \%)$ \\
\hline Submucosal invaded carcinoma & 93 & $(0.4 \%)$ \\
\hline Carcinoid tumor & 16 & $(2.9 \%)$ \\
\hline Lipoma & 3 & $(1.9 \%)$ \\
\hline Complications, $n$ (\%) & & \\
\hline Perforation & 21 & \\
\hline Post-ESD bleeding & 14 & \\
\hline
\end{tabular}

ages, the percentage of females increased $(p<0.01)$. There were no differences in tumor location and the tumor size. Furthermore, regarding the types of tumor, the percentage of pedunculated tumors decreased, while that of laterally spreading tumors increased after adoption $(\mathrm{p}<0.01)$ (Table 2).

\section{Comparison of methods to treat Tis carcinoma}

In surgically treated colorectal cancer patients, the number of Tis carcinomas significantly decreased from $75(5.5 \%)$ to $8(0.4 \%)$ after adoption of colorectal ESD ( $<<0.01)$ (Table 3$)$.

The most frequent method to treat Tis carcinoma before adoption was snare polypectomy with EMR, at 141 (65.3\%), followed by laparotomy, at $54(25.0 \%)$, laparoscopic surgery, at $18(8.3 \%)$, and transanal surgery, at $3(1.4 \%)$. After adoption, colorectal ESD was the most frequent method, at 154 (55.2\%), while the number of polypectomy with EMR decreased to 117 (41.9\%). Endoscopic procedures had been used for $97.1 \%$ of all Tis carcinomas. The number of surgical procedures was 8: 3 for almost-circumferential, laterally spreading tumors, and 5 for deep submucosal invasion identified on preoperative endoscopic diagnosis. All these procedures were laparoscopically performed (2.9\%) (Figure 1).

\section{Discussion}

It is known that opinions regarding Tis carcinoma are divided between Western countries and Japan [12]. Intramucosal carcinoma tends to be diagnosed as high-grade dysplasia in the former and welldifferentiated adenocarcinoma in the latter. However, even in the case of high-grade dysplasia, it is necessary to initiate treatment at the stage

Table 2: Clinical comparison of Tis carcinomas

\begin{tabular}{|c|c|c|c|c|c|}
\hline \multirow[b]{3}{*}{ Tis carcinomas } & \multirow{2}{*}{\multicolumn{2}{|c|}{$\begin{array}{c}1996-2005 \\
(n=1,537)\end{array}$}} & \multirow{2}{*}{\multicolumn{2}{|c|}{$\begin{array}{c}2006-2015 \\
(n=2,289)\end{array}$}} & \multirow{3}{*}{$\begin{array}{c}\text { P-value } \\
0.092 \\
\end{array}$} \\
\hline & & & & & \\
\hline & 216 & $(14.1 \%)$ & 279 & $(12.2 \%)$ & \\
\hline $\begin{array}{l}\text { Age, median } \pm \mathrm{SD} \text { (range), } \\
\text { years }\end{array}$ & $65.0 \pm 10.1$ & $(30-88)$ & $67.3 \pm 11.2$ & $(29-91)$ & 0.683 \\
\hline Sex (M:F ratio) & 162 & $: 54$ & 176 & $: 103$ & $<0.01$ \\
\hline \multicolumn{6}{|l|}{ Tumor location, $\mathrm{n}(\%)$} \\
\hline Cecum & 13 & $(6.0 \%)$ & 11 & $(4.0 \%)$ & 0.286 \\
\hline Ascending colon & 24 & $\begin{array}{c}(11.1 \\
\%)\end{array}$ & 33 & $(11.8 \%)$ & 0.804 \\
\hline Transverse colon & 20 & $(9.3 \%)$ & 31 & $(11.1 \%)$ & 0.502 \\
\hline Descending colon & 17 & $(7.9 \%)$ & 19 & $(6.8 \%)$ & 0.652 \\
\hline Sigmoid colon & 83 & $\begin{array}{c}(38.4 \\
\%)\end{array}$ & 94 & $(33.7 \%)$ & 0.276 \\
\hline Rectum & 59 & $\begin{array}{c}(27.3 \\
\%)\end{array}$ & 91 & $(32.6 \%)$ & 0.203 \\
\hline Tumor size \pm SD (range), mm & $18.6 \pm 13.3$ & $(3-95)$ & $21.0 \pm 15.7$ & $(3-127)$ & 0.088 \\
\hline \multicolumn{6}{|l|}{ Tumor morphology, n (\%) } \\
\hline Sessile & 67 & $\begin{array}{c}(31.0 \\
\%)\end{array}$ & 81 & $(29.0 \%)$ & 0.632 \\
\hline Pedunculated & 105 & $\begin{array}{c}(48.6 \\
\%)\end{array}$ & 101 & $(36.2 \%)$ & $<0.01$ \\
\hline Depressed & 3 & $(1.4 \%)$ & 5 & $(1.8 \%)$ & 0.992 \\
\hline Laterally spreading tumor & 41 & $\begin{array}{c}(19.4 \\
\%)\end{array}$ & 92 & $(33.0 \%)$ & $<0.01$ \\
\hline
\end{tabular}

Table 3: The percentage of surgically treated Tis carcinomas.

\begin{tabular}{|l|c|c|c|c|c|}
\hline & \multicolumn{2}{|c|}{$1996-2005$} & \multicolumn{2}{c|}{$\mathbf{2 0 0 6}$ - 2015 } & P-value \\
\hline $\begin{array}{l}\text { Surgery for colorectal } \\
\text { carcinoma }\end{array}$ & \multicolumn{2}{|c|}{1,369} & \multicolumn{2}{|c|}{2,093} & \\
\hline Tis carcinoma & 75 & $(5.5 \%)$ & 8 & $(0.4 \%)$ & $<0.01$ \\
\hline
\end{tabular}




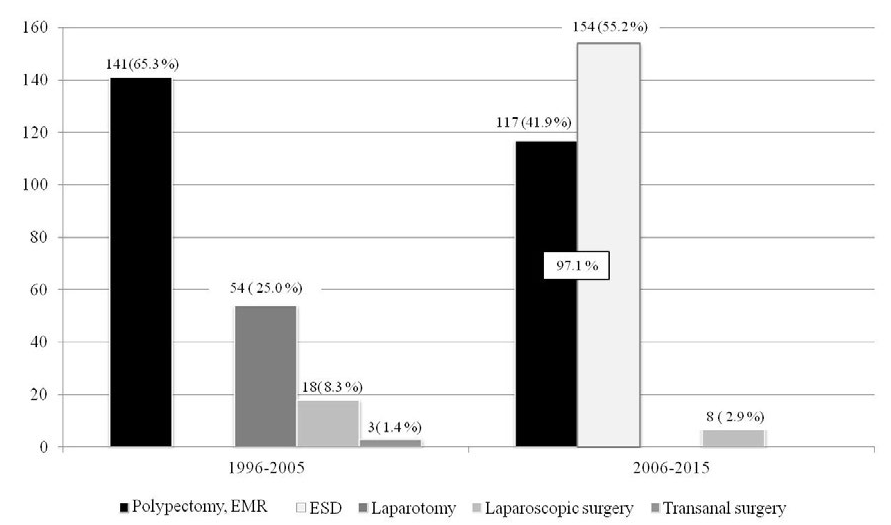

Figure 1: Methods to treat Tis carcinoma.

of intramucosal neoplasia not involving the risk of metastasis, as it may progress to cancer. On the other hand, T1 carcinoma involving lymph node metastasis in approximately $10 \%$ [2-4] is treated with bowel resection with lymph node dissection, in principle, except when endoscopically removed lesions confirm a markedly low risk of lymph node metastasis, indicating the sufficiency of observation without additional surgery [13]. Furthermore, even when the risk of lymph node metastasis is markedly low, surgery, rather than endoscopic procedures, may not be regarded as over-treatment, as T1 carcinoma is invasive [14]. In short, treatments for $\mathrm{T} 1$ and Tis carcinomas are based on surgical and endoscopic procedures, respectively [13], and it is desirable for both to be minimally invasive. In recent years, laparoscopic surgery has become the main treatment for the former, while colorectal ESD has been added for the latter. As 10 years have passed since colorectal ESD was adopted in our department, this study examined its effects on treatment for Tis carcinoma.

Although the number of Tis carcinomas increased after adoption of colorectal ESD, their number as a percentage of all colorectal cancers remained unchanged. Tis carcinoma-related changes also included: increases in the percentage of females and the percentage of laterally spreading tumors with a decrease in that of pedunculated tumors. The cause of the increased percentage of females and the cause of the decreased percentage of pedunculated tumors remained unclear.

Regarding methods to treat Tis carcinoma, the percentage of surgical procedures decreased from 5.5 to $0.4 \%$, and that of endoscopic procedures increased to $97.1 \%$ after adoption of colorectal ESD. Among the endoscopic procedures, colorectal ESD had been performed the most frequently, at $55.2 \%$, indicating that it had become the main treatment method for Tis carcinoma. On the other hand, the decrease in the number of polypectomy with EMR may be explained by an increased frequency of ESD for diseases that had previously been treated with polypectomy and EMR, in addition to a slightly reduced number of pedunculated polyps. While being a difficult technique, colorectal ESD is a useful treatment method that allows en-bloc resection even for lesions that cannot be removed by conventional methods. It also enables practitioners to perform en-bloc resection for laterally spreading tumors with a large diameter [15]. Therefore, it is likely to have contributed to further reducing the invasiveness of treatment for Tis carcinoma [16].

Not surgically, but endoscopically treating Tis carcinoma reduces patients' mental, physical, and financial burdens, while enabling medical professionals to avoid unnecessary surgical procedures, and treat other patients who need such procedures. From the viewpoint of surgery, the merit of colorectal ESD may be reducing the use of surgical procedures for Tis carcinoma, and consequently improving the efficiency of surgery [11].

Regarding study limitations, this study was conducted in a single facility, indicating the necessity of conducting further studies in multiple facilities and aggregating obtained data. Decreases in the number of surgical procedures for Tis carcinoma related to the adoption of colorectal ESD are likely to be marked if it has been adopted in multiple facilities with appropriate approaches, while they are limited in a single facility, as its annual number of unnecessary surgical procedures for bowel resection is also limited.

The important point is that practitioners should improve their endoscopic skills for diagnosis, while avoiding endoscopically treating T1 carcinomas with deep submucosal invasion, or surgically treating Tis carcinomas not requiring colon resection. At the same time, it is necessary to consider that, when dealing with circumferential lesions that may involve stenosis after colorectal ESD, or when the duration of this procedure is likely to be long, laparoscopic surgery may be more appropriate [17]. Priority should be given to the provision of safe and secure treatment for patients.

In conclusion, in our department, the percentage of surgical procedures for colorectal cancers diagnosed as Tis carcinoma decreased from 5.5 to $0.4 \%$ after the adoption of colorectal ESD 10 years previously. From the viewpoint of surgery, the merit of colorectal ESD may be further reducing the invasiveness of treatment for Tis carcinoma by reducing the use of surgical procedures.

\section{Conflict of interest}

No conflict of interest was declared by any of the authors.

\section{References}

1. Japanese Society for Cancer of the Colon and Rectum. (2013) Japanese Classification of Colorectal Carcinoma, $8^{\text {th }}$ edition. Tokyo: Kanehara.

2. Wang HS, Liang WY, Lin TC, Chen WS, Jiang JK, et al (2005) Curative resection of $\mathrm{T} 1$ colorectal carcinoma: risk of lymph node metastasis and long-term prognosis. Dis Colon Rectum 48: 1182-1192. [Crossref]

3. Nascimbeni R, Burgart LJ, Nivatvongs S, Larson DR (2002) Risk of lymph node metastasis in T1 carcinoma of the colon and rectum. Dis Colon Rectum 45: 200-206. [Crossref]

4. Yamamoto S, Watanabe M, Hasegawa H, Baba H, Yoshinare K, et al. (2004) The risk of lymph node metastasis in T1 colorectal carcinoma. Hepatogastroenterology 51: 998-1000.

5. Lee KH, Kim JS, Cheon KS, Song IS, Kang DY, et al. (2014) TisN0M1 sigmoid colon cancer: A case report. Ann Coloproctol 30: 141-146.[Crossref]

6. Hotta K, Fujii T, Saito Y, Matsuda T (2009) Local recurrence after endoscopic resection of colorectal tumors. Int J Colorectal Dis 24: 225-230. [Crossref]

7. Hotta K, Saito Y, Matsuda T, Shinohara T, Oyama T (2010) Local recurrence and surveillance after endoscopic resection of large colorectal tumors. Dig Endosc $22 \mathrm{Suppl}$ 1: S63-S68. [Crossref]

8. Sakamoto T, Matsuda T, Otake Y, Nakajima T, Saito Y (2012) Predictive factors of local recurrence after endoscopic piecemeal mucosal resection. J Gastroenterol 47: 635-640. [Crossref]

9. Tanaka S, Kashida H, Saito Y, Yahagi N, Yamano H, et al. (2015) JGES guidelines for colorectal endoscopic submucosal dissection/endoscopic mucosal resection. Dig Endosc 27: 417-434. [Crossref]

10. Tanaka S, Tamegai Y, Tsuda S, Saito Y, Yahagi N, et al. (2010) Multicente questionnaire survey on the current situation of colorectal endoscopic submucosal dissection in Japan. Dig Endosc 22(Suppl.1): S2-S8. [Crossref] 
11. Kobayashi N, Saito Y, Uraoka T, Matsuda T, Suzuki H, et al. (2009) Treatment strategy for laterally spreading tumors in Japan: before and after the introduction of endoscopic submucosal dissection. J Gastroenterol Hepatol 24: 1387-1392. [Crossref]

12. Yao T, Shiono S (2016) Differences in the pathological diagnosis of colorectal neoplasia between the East and the West: Present status and future perspectives from Japan. Dig Endosc 28: 306-311. [Crossref]

13. Japanese Society for Cancer of the Colon and Rectum (2014) JSCCR Guidelines 2014 for the treatment of colorectal cancer. Tokyo: Kanehara.

14. Saitoh Y, Inaba Y, Sasaki T, Sugiyama R, Sukegawa R, et al. (2016) Management of colorectal T1 carcinoma treated by endoscopic resection. Dig Endosc 28: 324-329. [Crossref]
15. Hotta K, Saito Y, Fujishiro M, Ikehara H, Ikematsu H, et al. (2012) Impact of endoscopic submucosal dissection for the therapeutic strategy of large colorectal tumors. J Gastroenterol Hepatol 27: 510-515.[Crossref]

16. Terasaki M, Tanaka S, Oka S, Nakadoi K, Takata S, et al. (2012) Clinical outcomes of endoscopic submucosal dissection and endoscopic mucosal resection for laterally spreading tumors larger than $20 \mathrm{~mm}$. J Gastroenterol Hepatol 27: 734-740. [Crossref]

17. Kure K, Kawai M, Ishiyama S, Kamiyama H, Tomiki Y, et al. (2015) Complete endoscopic submucosal dissection of a giant rectal villous adenocarcinoma with electrolyte depletion syndrome. Case Rep Gastroenterol 9: 126-131. [Crossref]

Copyright: (C2016 Tomiki Y. This is an open-access article distributed under the terms of the Creative Commons Attribution License, which permits unrestricted use, distribution, and reproduction in any medium, provided the original author and source are credited. 